\section{Today I Saw the Dragon Fly \\ (Continued from page 17)}

house at the time, the nymph was laid on a box where it quickly became inert-dried out and to all apparances, dead. Returning in an hour it was quite surprising to see the cast form still clinging to the box and the insect, we had thought dead, jubilantly clad in a new blue coat and lacey wings. It was taken outside where it immediately flew off.

Quite as surprising and dramatic was another chapter of this life. An adult damsel-fly lit on the portion of a small rush above the water and then resolutely drew itself "hand by hand" down into the depths. The reason for this irrational appearing behavior soon became apparent. With a probing abdomen the eggs were deposited on the stem-to hatch under water.

Again there is not time to wait and see if the insect would release itself and rise to the surface, and gauzy wings once more take to the air for a few more days in the sun- light with the male who remained aloft. But I rather doubt it. The cycle of life was complete and a tiny discarded craft would disintegrate in the water.

\section{Fox and Rooster Ernest Bishop, Oxbow}

WHILE returning home about ten o'clock one night in early fall, I passed the Peter Ward farm about half a mile wher. I distinctly heard the chortle of a ooster. My curiosity being aroused I stopped the team, and guided by the continued squawks of the rooster I hurried in that direction by the dim light of the moon. When I got close enough, to my surprise, I found the rooster in the grip of a small kit fox who held him by the wattle and was leading him to his den.

The rooster was too heavy for the little fox to carry so he used a wiser and easier method. I was quite close before the fox let go his hold. I caught the bird, nothing worse for his experience, and took him to his owner.

\title{
DAMAGE BY DEER EXTENSIVE
}

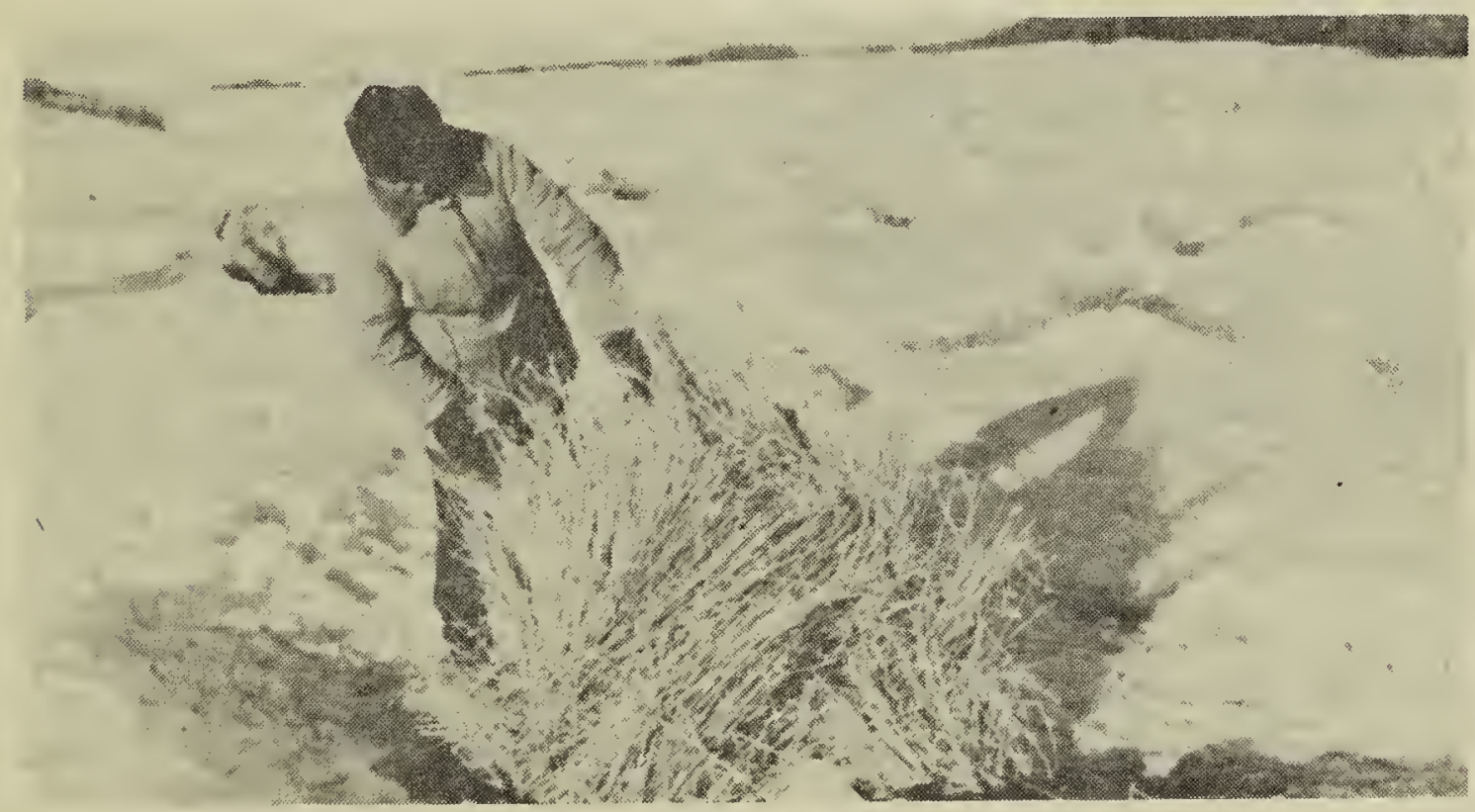

CONSIDERABLE damage was done throughout the winter in various sec4 tions of the province to the numerous fields of grain which are still in swath or in stook. The photograph shows W. A. Brownlee, field officer of the Department of Natural Resources, searching in vain for wheat heads among the snow-covered stooks on the farm of J. R. Kwasnica near Reynaud. Bill explains that in the many areas north of Humboldt, where the snowfall has been heavy, the deer have "yarded up" and have stripped sheaves bare of grain-filled heads. 